\title{
Methodological and ethical issues in conducting qualitative research with children and young people: A literature review
}

\author{
Susan Kirk* \\ School of Nursing, Midwifery and Social Work, University of Manchester, Coupland 3, Oxford Road, Manchester M13 9PL, UK
}

Received 14 April 2006; received in revised form 28 July 2006; accepted 10 August 2006

\begin{abstract}
Background: There is an increasing interest in involving children in research that has been influenced by the recognition of children's rights and by the reconceptualisation of children within the social sciences as active agents rather than as the objects of research.

Objectives: To review the methodological and ethical issues involved in conducting qualitative research with children and to consider the implications for nursing research in light of recent debates within the social sciences.

Design: Narrative literature review using a systematic search of computerized databases.

Data Sources: Published papers, key texts, reports and policy documents that relate to the methodological and ethical issues in conducting qualitative research with children.

Results: There are three ethical issues in relation to conducting research with children: power relations, informed consent and confidentiality. Two key methodological issues are identifiable in relation to conducting research with children. One is epistemological and relates to the different cultures of childhood and adulthood and the second relates to the heterogenous nature of childhood itself. Novel techniques and task-based activities are being increasingly used to establish rapport and as a method of data collection.

Conclusion: There are both differences and similarities in conducting qualitative research with children and with adults but often the similarities have been overlooked and the differences overstated. Nursing and other health-related researchers conducting research with adults could learn much from children's researchers, particularly in terms of sensitivity to ethical issues. Nursing research need to consider the methodological issues that have been debated in the social sciences and to critically reflect on the use of novel techniques in qualitative research.
\end{abstract}

(C) 2006 Elsevier Ltd. All rights reserved.

Keywords: Children; Research methods; Qualitative research; Review

\section{What is already known about the topic?}

- There is an increased emphasis on involving children and young people directly in research.

- There are divergent views on whether there are particular ethical issues relating to researching children.

\footnotetext{
*Tel.: + 44161275 5347; fax: +441612757566.

E-mail address: sue.kirk@manchester.ac.uk.
}

- 'Child friendly' data collection techniques are being developed to allow adult researchers to access children's worlds.

\section{What this paper adds}

- It brings recent debates in the sociology of childhood into the nursing/health-related arena for consideration by researchers. 
- It highlights the transferability of the ethical principles underpinning research with children to research with adults.

- It identifies the need for nurse and other healthrelated researchers to critically analyse the use of novel techniques in research.

\section{Introduction}

There has been a long tradition of research concerned with children. However, this body of research has been largely about children rather than involving them directly (Hill, 1997). Instead children's lives have been explored through the views and understandings of their adult caretakers or they have been subsumed within research on the family (Christensen and James, 2000). The reasons for not conducting research with children in the past centre on two issues - firstly a belief that data obtained from children was unreliable and secondly ethical concerns over their vulnerability to exploitation by researchers.

Data obtained from children were viewed as unreliable and invalid because it was believed that children were too immature to understand their worlds, and lacked the necessary verbal and conceptual abilities to convey their experiences (Docherty and Sandelowski, 1999). They were assumed to be suggestible and incapable of distinguishing between fantasy and reality (Punch, 2002a). However, there is now a growing body of evidence that demonstrates that children can be competent participants in the research process as long as researchers recognise the ways in which children communicate and facilitate their participation (Mauthner, 1997; Thomas and O'Kane, 1998). As with adult participants, children's accounts have their own validity in terms of being their perspective on how the world appears to them and are narratives created within the context of an interview and may not be accurate representations of events. (Harden et al., 2000b; Punch, 2002a).

In the past concerns about the ethics of conducting research with children were a common reason for using adults as proxies as it was felt that children were particularly vulnerable to exploitation by researchers (Beresford, 1997). However, over the last 10 years the literature about the ethics and practice of research with children within the social sciences has increased and good practice guidelines have been developed specifically in relation to children (Alderson, 1995; Beresford, 1997; Mahon et al., 1996; National Children's Bureau, 2003; Ward, 1998). This has been stimulated by the increased interest in children and children's lives particularly in sociological research and writing on children. There has also been a growth of child centred research in nursing and other disciplines (for example,
Beresford and Sloper, 2003; Coyne, 1998; Dixon-Woods et al., 2002; Freed et al., 1998; Kyngas, 1998; Litt, 1998; Miller, 2000; Sloper and Lightfoot, 2003; Woodgate and Kristjanson, 1996). Indeed in the 1990s major government funded research programmes both in the United Kingdom and North America emphasised the importance of obtaining children's views (National Insitutes of Health, 1997). This increased emphasis on involving children in research has been influenced by the recognition of children's rights and by the reconceptualisation of children within the social sciences.

\subsection{Children's rights}

In the United Kingdom (UK) there has been a growing recognition of children's rights particularly in relation to their involvement in decision making as a result of the United Nations Convention on the Rights of the Child (United Nations, 1989) and the 1989 Children's Act. It is now noticeable that policy and practice initiatives in health, social work and education are highlighting children's interests and views (Department of Health, 2002; Department of Health and Department for Education and Skills, 2004). This is in keeping with the increasing emphasis since the 1980s on consumerism in public policy which in more recent years has included incorporating the views of children in service development and evaluation. There is however, an ambiguity in how childhood is conceptualised as on the one hand children are still seen as being in need of protection and on the other as being autonomous individuals which is also evident in writings on research methodology (Jans, 2004).

\subsection{The reconceptualisation of children}

How children and childhood are conceptualised has changed from one dominated by socialisation theory and developmental psychology. Socialisation (the social process through which an individual becomes a member of a social group) was the major framework within which sociologists studied children (Waksler, 1991). However, this became criticised for its assumption that children were 'empty' and unfinished, ready to be 'filled' with the ideas of the group/society into which they had been born, and a failure to appreciate that children experience aspects of the world in their own terms (Waksler, 1991: James and Prout, 1997). Developmental psychology presented a universal developmental perspective on childhood, drawing extensively on the theories of Piaget (James, 2001). This perspective influenced thinking within both sociology and psychology and was based on ideas of natural growth. Development was viewed in terms of a progression from simplicity to complexity of thought and from irrational to rational behaviour (James and Prout, 
1997). Children were conceptualised as incompetent, immature, incomplete and as passive and conforming objects of a one-way socialisation process (Waksler, 1991; James and Prout, 1997; James, 2001). In the late 1980 s there was a questioning of these theories of socialisation and developmental psychology and a growing interest in childrens' experiences of childhood (Brannen and O'Brien, 1995; Mauthner, 1997; Mayall, 1994). This new way of thinking about children and childhoods was based on interactionism and social contructionism and influenced by developments in children's rights which reframed the social status and position of children (James and Prout, 1997; James, 2001). This perspective sees childhood as being socially constructed and emphases the social, cultural and historical variability of childhood (James and Prout, 1997). Children are seen as possessing different experiences and knowledge to adults and as being competent social actors, actively involved in responding to and shaping their social worlds (Waksler, 1991; James and Prout, 1997; Christensen and James, 2000; Hutchby, 2005).

Consequently in research children are now constructed as active agents rather than passive objects of research (Beresford, 1997; Hill, 1997). There has been an increasing awareness that it is inappropriate to have adults acting as proxies for children and that to learn about their experiences we need to elicit their representations and seek information directly from them (Mahon et al., 1996). This reconceptualistion has been supported by research that has demonstrated that adults and children have different views and experience events and situations differently, suggesting that adult proxies cannot give valid accounts of children's social worlds (Beresford, 1997; Dixon-Woods et al., 1999).

Although there has been some consideration within the nursing literature of the methodological and ethical issues relating to conducting research with children this has tended to focus on particular data collection methods such as interviewing and focus groups (Baumann, 1997; Bricher, 1999; Coyne, 1998; Deatrick and Faux, 1989; Docherty and Sandelowski, 1999; Faux et al., 1988; Horner, 2000; Kortesluoma et al., 2003). In particular there has been a lack of appreciation of the sociology of childhood and the current methodological debates over whether carrying out research with children does necessarily entail using different methods to those used with adults (Christensen, 2004; Punch, 2002b). It has been asserted that research with children should not take for granted a child-adult distinction. Rather it is more important that the methods chosen should be appropriate for the people involved in the study, their social and cultural context and the research question.

The aim of this paper is to review the methodological and ethical issues involved in conducting qualitative research with children and young people and consider the implications for nursing and health researchers in light of recent debates within the social sciences. The paper will argue that there are many similarities in conducting research with children and adults which are often overlooked and that all researchers can learn from the attention paid both to the methodological and particularly the ethical issues around conducting research with children.

\section{Method}

A comprehensive, narrative review of the literature was undertaken in order to identify publications that have examined the methodological and ethical issues in relation to conducting qualitative research with children and young people. The search terms/strategies used for the review and the bibliographic databases that were searched are shown in Fig. 1. In addition, key texts, reports and policy documents relating to conducting research with children were reviewed.

\subsection{The ethical issues}

Ethical issues in relation to conducting research will be considered in relation to three issues: power relations, informed consent and confidentiality. These ethical issues are not unique to children and many are present when conducting research with adults. However it has been argued that there are important differences in how they are approached with children due to children's understanding and experience of the world being different to adults, differences in how children communicate and because of the more acute unequal power relationships that exist between adult researchers and child participants (Mauthner, 1997; Thomas and O'Kane, 1998). As will be noted later others however, do not draw such a sharp distinction between conducting research with children and with adults (Harden et al., 2000b; Christensen, 2004).

\subsection{Power, exploitation and protection}

There is an awareness that the adult centredness of most societies and the unequal power relations that exist between children and adults are duplicated in the research process (Harden et al., 2000b; Morrow and Richards, 1996; Punch, 2002b). This has led to concerns over how free children feel to refuse to participate in a study, to withdraw during the research or even to give their own views and experiences to adult researchers (McCrum and Bernal, 1994). This is a particular issue for social researchers as the most vulnerable children in society may be involved in research, for example, disabled children or 'looked-after' children (Beresford 1997; Davis 1998). In addition in most studies where a 
Criteria : English language only

Databases searched:

Medline 1966-October 2004

HMIC (Health Management Information Circular) to October 2004

CINAHL 1982-2004

BNI 1985-2004

PsycINFO 1985-2004

ASSIA 1987-2004

Sociological Abstracts 1963-2004

Social Services Abstracts 1980-2004

Sociology (Sage) 1982-2004

Sage Social Research Methodology Database

Social Sciences Index February 1983-June 2004

Social Sciences Citation Index 1985-2004

\section{Search Strategy :}

Free text searches looking for keywords in title or abstract of records:

(research methods or research methodology) AND (child* or adol ${ }^{\star}$ )

Thesaurus searches:

The following thesaurus terms were identified and searches carried out:

CINAHL

(CHILD OR ADOLESCENCE) AND RESEARCH METHODOLOGY

BNI

CHILDREN AND RESEARCH METHODS

ASSIA

CHILDREN AND METHODOLOGY

SOCIAL SERVICES ABSTRACTS AND SOCIOLOGICAL ABSTRACTS

(CHILDREN OR ADOLESCENTS) AND RESEARCH METHODOLOGY

MEDLINE

(CHILDREN OR ADOLESCENT) ANLINURSING METHODOLOGY RESEARCH OR METHODS OR SOCIAL SCIENCE)

PsycINFO

METHODOLOGY

HMIC

RESEARCH METHODS/METHODOLOGY

Fig. 1. Literature search terms and strategies.

child is under 16 years of age parents or other adults act as gatekeepers giving consent to their child's participation (Harden et al., 2000b). While such gatekeepers may be acting as protectors there is the potential that they may deny children the opportunities for participation or conversely coerce them into participating (Harden et al., 2000b). Fig. 2 presents a number of ways that have been proposed for managing the inherent power differentials between child participants and adult researchers (Alderson, 1995; Horner, 2000; Mahon et al., 1996; Mauthner, 1997; Morrow and Richards, 1996; Ronen et al., 2001; Thomas and O'Kane, 1998).

It has also been identified that there is an obligation on adult researchers to ensure that children do not suffer harm from participating in research (Morrow and Richards, 1996). As with all research participants there 


\begin{abstract}
Using methods that allow children to feel part of the research process and which give them the maximum opportunity to provide their views.

Being responsive to children's own agendas.

Involving children as part of the research team.

Using group interviews.

Checking on children's willingness to participate throughout the interview (including being aware of nonverbal cues such as body language).

Rehearsing with children how to decline participating or answering particular questions.

In interview studies giving children control over tape recorders.
\end{abstract}

Fig. 2. Ways of managing the power differential between children and adults in research.

is the potential that taking part in research may cause children distress and researchers are seen as having an ethical responsibility to be prepared to contend with any negative emotions that children may experience as a result of participating such as conflict, guilt, threat to self-esteem, fear of failure, embarrassment.

\subsection{Informed consent}

Informed consent is viewed as being based on three aspects: firstly that potential participants gain knowledge through the provision of information they can understand; secondly that consent is voluntarily given and thirdly that the potential participant has the capacity or competence to give their consent (Beresford, 1997). These three issues: information giving, voluntary participation and competency have all received particular emphasis in child-centred research. The need to develop appropriately tailored information in different forms for children with a range of developmental/ chronological ages and needs has been recognised (Beresford, 1997; Davis, 1998). Particular difficulties identified are conveying to children what it means to take part in a research study and that their participation is likely to have no direct benefit to them (Kortesluoma et al., 2003; Mauthner, 1997). The second aspect-the importance of ensuring that consent is voluntarily given has been considered in the last section. The third aspect that underpins informed consent, competency, has been of great concern to researchers particularly in recent years with the recognition that it is unacceptable to only obtain consent from parents. In the UK researchers have drawn on legal judgements given in relation to health and social care issues. This guidance means that there is no age stipulated when children aged under 16 years can give consent, instead the emphasis is on the person obtaining consent assessment of the competency of the individual child (Beresford, 1997). In social research informed consent is regarded as a process with the researcher continually checking that the child or young person wishes to continue participating (Mahon et al., 1996).

\subsection{Confidentiality and disclosure}

Confidentiality is seen as a problematic issue in family research where researchers are interviewing family members separately or together. Obtaining a separate space away from the main family room can be a sensitive issue as the family may live in cramped housing situations or some families may not see children as having a need for privacy (Mauthner, 1997).

The boundaries to confidentiality have received attention in the child research field largely because of the potential for a child to disclose information that suggests that they or another child may be 'at risk'. Although there are researchers who treat all information as confidential, most experts consider that complete confidentiality cannot be guaranteed and that researchers have a duty to pass on information if they feel a child is 'at risk' (Beresford, 1997). It is considered good practice to highlight the limits to confidentiality in information sheets as well as providing information on how the researcher will manage disclosures (Alderson, 1995; Beresford, 1997; Davis, 1998).

Ethical issues appear to be of greater concern in the child research literature because of the construction of children as vulnerable and incompetent. While the importance of ethics have been acknowledged some have questioned whether 'special' child-centred ethics 
are required. It has been proposed that if the Piagetian view of children as not yet competent or fully functioning moral beings is rejected then it follows that there is no need to see children as 'being a separate species for ethical purposes' (Harden et al., 2000b). Instead it is argued that ethical issues should revolve around children's unequal power relationships with adults rather than beliefs about their innate difference (Punch, 2002b).

\section{Methodological issues}

There appear to be two central methodological issues in relation to conducting research with children. One is epistemological and relates to the different cultures of childhood and adulthood and the second relates to the heterogenous nature of childhood.

\subsection{The different worlds of adulthood and childhood}

The way in which researchers conceive childhood shapes their research in terms of the extent to which they view children as being 'different' from adults as well as how they perceive the status of children in society (Harden et al., 2000b; Punch, 2002b). In recent years social scientists have conceptualised childhood as being different not in terms of it being a stage towards adulthood but as being another culture (Harden et al., 2000b). Consequently the differences between adults and children are seen as extending far beyond their developmental differences to their different perspectives and constructions of the world. Consequently it has been argued that adult researchers cannot understand the world from a child's point of view (Christensen, 2004; Punch, 2002b). Solberg (1996) has asked what kind of knowledge is it possible for adults to gain about children? Is it possible for an adult to make an accurate representation of the child's perspective? It has been highlighted that in most studies adult researchers collect and interpret data and consequently what is produced is an adult interpretation of the child's social world (Davis, 1998; Punch, 2002b). A number of ways of managing the different cultures of childhood and adulthood for researchers have been proposed. These are adopting different researcher roles, reflexivity and involving children at all stages of the research process.

A number of researcher roles (for example, non authoritarian adult and 'least adult') have been proposed to enable researchers to interact with children although there is disagreement over whether this actually facilitates interaction (Davis, 1998). There have been debates about whether researchers should take the 'least-adult role'; i.e. 'pretending' to be a child or whether they should try to befriend their child participants. Opponents argue that befriending is problematic because of the inherent power relations and that friendship is usually regarded as a relationship between equals (Harden et al., 2000b). While some researchers have suggested that observation could be the most appropriate method for studying children and childhood because it would allow a more complete picture of children's culture to emerge, others contend that children are unlikely to accept adults as one of them or to be able to ignore their presence and that therefore it would be impossible for an adult researcher to be a full participant in children's social worlds (Christensen 2004).

Reflexivity is seen as another means of managing the culture gap and enabling adult researchers to be aware of their own assumptions about childhood and how this may influence the research process and their understanding of those they study (Davis, 1998; Harden et al., 2000 b). It has been proposed that researchers have to challenge that they 'know' what childhood is like just because they were once a child as they will have forgotten and abandoned elements of this culture overtime and childhood itself will have changed in the intervening years (Punch, 2002b).

A third way that has been proposed of managing the culture gap between children and adults is involving children in the research process itself from defining the research questions, through data collection and analysis to dissemination (Morrow and Richards, 1996; Ward, 1998; West, 1999). While there are now many examples of children acting as data collectors, it has been suggested that it is problematic to completely involve children (and adult subjects) in data analysis because it involves access to concepts, theories and scholarly knowledge unavailable to most research participants (Harden et al., 2000b; Punch, 2002b). However, it may be that it is more possible to involve participants, be they children or adults, in analysing data from more policy and service-orientated research.

\subsection{Different childhoods}

In the literature children and childhood are sometimes presented as being part of one homogeneous group in order to contrast childhood and adulthood (Davis, 1998). However, there is increasing recognition that they are a highly differentiated group with consequent methodological implications (Hill, 1997). There are different childhoods comprised of different relationships, interactions, and perceptions (Davis, 1998). There are also other differences that researchers need to take account of in terms of children's macrosocial characteristics (such as gender, chronological age, race, disability) as well as differences in their cognitive development, life experiences and communication competence (Hill, 1997). Therefore researchers have to recognise both the 
culture of childhood and the culture of the individual child (Harden et al., 2000b; Punch, 2002b).

Consideration of the implications for research of chronological age and cognitive development has received a great deal of attention in the literature. As noted earlier in this paper, in the past questions were raised about the accuracy, suggestibility, consistency and completeness of data obtained from children as it was argued that they had not fully developed the capabilities to provide trustworthy accounts of their experiences (Docherty and Sandelowski, 1999). However, there is more awareness now that even very young children can recall events (Docherty and Sandelowski, 1999). Although very young children may have more limited communication capabilities when compared with older children, it has been proposed they are competent in ways often not acknowledged. Indeed Alderson and Goodey (1996) suggest that children with health problems may mature quickly and their experiences increase their understanding. Research examining children's talk within the context of their peer groups has demonstrated children's competencies in social interaction (Hutchby, 2005).

There are inherent differences between adults and children, for example, children have a different and sometimes a more limited vocabulary and understanding of words (Punch, 2002b). Sociologists have noted that the developmental model of childhood is pervasive in our everyday thinking (for example, the use of standardised tests to assess child development, the organisation of children on basis of their chronological age) (James et al., 1998). While James et al. (1998) do not deny that there are differences between children at different ages, they argue that age should be seen as a social rather than a natural variable in research. Instead it has been argued that researchers should to some extent try and ignore a child's age so that assumptions about age do not influence their approach and instead that they should emphasise the 'situational contexts within which children act' (Solberg, 1996). However, it appears that developmental models remain influential as demonstrated by how interview studies often set a lower limit of seven or eight years of age because it is surmised that younger children are unlikely to provide 'useful' data (Hill, 1997). This is partly based on Piagetian ideas about 'concrete' thinking.

As previously discussed children are diverse in more ways than age differences (Punch, 2002b). Other differences such as social class, gender, disability, ethnicity or culture also have to be taken into account by researchers. Hill (1997) has noted that many studies of black children have been criticised for failing to take account of their ethnic background and for using white interviewers. The establishment of rapport and data generation can also be influenced by the interaction between a child's gender and that of the researcher
(Hill, 1997; Mahon et al., 1996) — an issue that has also been highlighted in feminist research. Matching interviewer and interviewee on the basis of gender or ethnicity has been proposed as one option (Mahon et al., 1996). However, this has been criticised for not only its impracticality but also because it may be based on the reseacher's assumptions on what the key differences are between interviewer and interviewee (Harden et al., 2000b).

The different worlds of childhood and adulthood coupled the power differentials and socio-demographic differences can also mean that building rapport can be problematic (Mahon et al., 1996; Punch, 2002b; Richman, 1993; Kortesluoma et al., 2003). Suggestions to assist the development of trust and rapport include showing warmth and interest, asking easy warm-up questions (for example about their interests) (Richman, 1993). Drawing and other novel methods developed from participatory rural appraisal are often used in qualitative research with children not just as a means of developing rapport but as data collection methods in their own right.

\subsection{The use of novel methods and techniques}

The key objective for researchers is to use tools that enable children to be active participants in the research process and which offer them the maximum opportunity to put forward their views (Davis, 1998). While using appropriate methods is of concern for all researchers there appears to be great enthusiasm within children's research to develop and use fun, 'child-friendly' methods (Punch, 2002b). These 'task-centred' activities have become common place in qualitative research with children and have been influenced by participatory rural appraisal (PRA) methods and by practitioners working with troubled children. The use of these methods are underpinned by beliefs that while children are similar to adults they have different expertise and competencies (James et al., 1998; Punch, 2002b). In particular it has been proposed that children are more used to communicating through pictures and stories (Davis, 1998; Mauthner, 1997). As a result researchers have employed structured activities as an alternative to interviews based on a belief that they are more appropriate for children's skills and enable them to be active participants in the research process (see Fig. 3) (Punch, 2002b). Examples of these novel techniques include: sentence completion exercises, diary completion, story writing, drawing and taking photographs or video recordings.

However, the benefits and the drawbacks of these novel techniques have not always been scrutinised and they have been frequently adopted with insufficient critical reflection (Punch, 2002b). Questions now being asked by social scientists are: what do they say about how children are constructed? Are they really fun? Do 


\begin{tabular}{|c|c|}
\hline Rationale & Underlying assumption \\
\hline $\begin{array}{l}\text { To sustain interest and avoid } \\
\text { boredom }\end{array}$ & $\begin{array}{l}\text { Children prefer 'fun' methods. } \\
\text { Children are more competent at these } \\
\text { methods. } \\
\text { Children (especially younger children) may } \\
\text { have a shorter attention span. } \\
\text { Children are more used to visual and written } \\
\text { techniques. }\end{array}$ \\
\hline To encourage expression & $\begin{array}{l}\text { They encourage children to express their } \\
\text { views freely to an adult researcher. } \\
\text { They foster rapport and enable children to feel } \\
\text { more at ease. } \\
\text { They enable children to express feelings or } \\
\text { needs that they are reluctant to express } \\
\text { verbally. }\end{array}$ \\
\hline $\begin{array}{l}\text { As a means to lessening the } \\
\text { imbalance in power between adult } \\
\text { researchers and child participants }\end{array}$ & $\begin{array}{l}\text { They may lessen the power relationship } \\
\text { imbalance as the interaction is between the } \\
\text { child and the paper rather than with an adult } \\
\text { researcher. }\end{array}$ \\
\hline
\end{tabular}

Fig. 3. Rationales and assumptions in the use of novel techniques in research with children.

they generate useful data? What are the implications for analysis of the data they generate?

The need to create special research techniques for children is premised on the belief that communicating with them is more difficult than with adults and that these techniques will somehow reveal some truth not accessible through talk (Harden et al., 2000b). This constructs children as 'other' in methodological terms with a consequent need to use novel or different methods. As Hill (1997) and Punch (2002b) note this has the potential of diminishing the position of children as independent actors in assuming that they are not capable of ordinary conversation like adults or in engaging with the methods used with adults. Moreover Punch (2002b) has commented that it is somewhat paradoxical that within the new sociology of childhood many of those who have called for novel research techniques with children are also those who emphasise the competence of children. This she suggests raises the question-if children are competent social actors then why do we need special 'child-friendly' methods to communicate with them?

These techniques are ability and enjoyment dependent. There is an assumption with them that they are 'fun' and that, for example, all children enjoy drawing. This may not be the case or they may have impairments that would make drawing problematic. Indeed Coyne
(1998) found that some children did not want to draw because they either saw it as a test or disliked drawing. Backett-Milburn and McVie (1999) discovered that limitations in drawing ability limited what children could 'say' in their pictorial representations. It is therefore questionable that drawing is a more effective method of communicating with a child (Harden et al., $2000 \mathrm{~b})$. Another issue is how are the data generated analysed? It presupposes that researchers have the required skills to analyse drawings (Harden et al., 2000b). A number of writers have noted that researchers need to take care that they do not misinterpret or impose an adult interpretation by asking the child themselves to talk about what the drawing means to them (BackettMilburn and McVie, 1999). Indeed Veltman and Browne (2002) in their review of the use of drawings in the identification of child abuse cautioned against over interpretation, concluding that drawings are best used as ice breakers or to aid recall of events. Harden et al. (2000b) have similarly recommended that they are best used as a stimulus to talk rather than as evidence in their own right. The use of cameras or camcorders is not as ability dependent as drawing and may provide access to aspects of children's lives that might otherwise be hidden (Punch, 2002b). As with drawings, children's reasons for taking particular pictures would need to be explored with them. 


\subsection{Conducting research with children: Different or the same as conducting research with adults?}

The differences and similarities in conducting research with children and adults are summarised in Fig. 4 (Punch, 2002b). Many of the ethical issues salient in conducting social research with children are common to participants of any age, for example, informed consent. However, when conducting research with children ethical issues present themselves more sharply partly because children's experience and understanding of the world is different from adults and partly because they communicate in different ways (Thomas and O'Kane, 1998). A fundamental issue relates to the different power relationships and the complexities that this creates for researchers. Thomas and O'Kane (1998) identify the following complexities. The process of obtaining consent is more complex as it may be necessary for both adults and children to give consent. Confidentiality is more complex as adults may expect to be told about the private lives and thoughts of children under their care. Protection from abuse is more complicated as children may be less able to protect themselves than most adults.

Some social science researchers consider that research with children is the same as adults and that researchers should not assume that particular methods are needed for research with children or that a different set of ethical standards are required (James et al., 1998; Christensen, 2004). However, this view has been criticised for not adequately addressing the inherent power imbalances (Punch, 2002b). Punch (2002b) identifies three broad areas of explanation for why research with children is different to research with adults. The first reason relates to the marginalized position of children in an adult-centred society which means that they experience unequal power relations. Secondly adults perceive children to be different and their assumptions and attitudes affect their behaviour. Consequently, researchers' assumptions about the position of children in society affects the methods chosen and how data is interpreted. Thirdly there are inherent differences between children and adults-children have a limited and different use of vocabulary and understanding of words; they usually have less experience of the world; and they may have a shorter attention span. Punch (2002b) argues that it is too simplistic to see research with children as being either the same or different from adults and that it should be seen as a continuum dependent on the individual child, the research context and the research questions.

\section{Conclusion}

This review suggests while there are differences and similarities between conducting qualitative research with children and with adults, often the similarities have been overlooked and the differences overstated. Indeed

\begin{tabular}{|l|}
\hline \multicolumn{1}{|c|}{ Differences in conducting research with children and adults } \\
\hline Children's views of the world are diffent to adults (a different culture). \\
A greater range in cognitive development. \\
A greater range in level of communication competency. \\
Rapport more difficult to develop. \\
Adults play a greater role as gatekeepers. \\
Power relations more problematic due to the position of children in society. \\
More emphasis on the use of 'special' methods to enable meaningful participation.
\end{tabular}

\begin{tabular}{|l|}
\multicolumn{1}{|c|}{ Similarities in conducting research with children and adults } \\
\hline Respect of individuality \\
Need to take account of major group differences (age, gender, ethnicity etc) \\
The use of appropriate research methods \\
Need to take account of the research context \\
Need for researcher not to impose their own views and interpretations \\
Concerns over rigour \\
Establishment of rapport between participant and researcher \\
The importance of clarity of research tools and questions. \\
The need to obtain informed consent. \\
Confidentiality. \\
Protection from exploitation and harm. \\
Management of disclosure.
\end{tabular}

Fig. 4. Comparison of the differences and similarities in conducting qulitative research with children and adults. 
nursing and other health-related researchers conducting research with adults could learn much from children's researchers in terms of their sensitivity to ethical issues and from those methodological issues that extend beyond conducting research with children to conducting research with adults. Children's researchers highlight good practice, particularly in relation to ethics, with close attention paid to the process of obtaining informed consent and to providing understandable information for research participants. Practical issues such as ensuring the clarity of the language used in information sheets, research tools and interview questions are important issues for all nursing and health related researchers, as is an awareness of differences in participants' cognitive and language abilities. Attention to the unequal power relations between participants and researchers is also applicable to research with adults. The novel techniques that are often used in qualitative research with children could also be useful in adult research to help participants engage with the research topic and facilitate communication. Indeed Punch (2002b) has noted that it would be more appropriate to call them 'research participant centred' methods particularly given that some of them have been adapted from adult-focused PRA.

As Woodgate (2001) has noted most child health research has been based on psychological notions of individual development. Nursing research has also been largely underpinned by this developmental model and has not taken account of recent thinking in sociology. As a result nursing research has often lacked reflexivity over what insight adult researchers can obtain into children's worlds. Nursing and other health-related researchers have often not made transparent their epistomological assumptions about childhood and how these have determined the role they have taken, the methods chosen and their interpretation of data. They also need to critically reflect on the use of novel techniques as these methods have tended to be adopted uncritically. These methods may have a place in qualitative research with children but what place? Their usefulness may lie in helping researchers to establish rapport with participants rather than as a means of accessing their social worlds. Perhaps they may be more useful for service development (like PRA) than academic research. Their intuitive and seductive appeal should not blind us to considering whether they are being used systematically and rigorously or whether they produce data of sufficient depth to develop new knowledge.

\section{References}

Alderson, P., 1995. Listening to children: Children and Social Research Ethics. Barnados, London.
Alderson, P., Goodey, C., 1996. Research with disabled children: how useful is child centred ethics. Children and Society 10, 106-116.

Backett-Milburn, K., McVie, L., 1999. A critical appraisal of the draw and write technique. Health Education Research 14, 387-398.

Baumann, S., 1997. Qualitative research with children. Nursing Science Quarterly 10, 68-69.

Beresford, B., 1997. Personal Accounts: Involving Disabled Children in Research. Social Policy Research Unit, New York.

Beresford, B., Sloper, P., 2003. Chronically ill adolescents experiences of communicating with doctors: a qualitative study. Journal of Adolescent Health 33, 172-179.

Brannen, J., O'Brien, M., 1995. Childhood and the sociological gaze: paradigms and paradoxes. Sociology 289, 729-737.

Bricher, G., 1999. Children and qualitative research methods: a review of the literature related to interview and interpretative processes. Nurse Researcher 6, 65-77.

Christensen, P., 2004. Children's participation in ethnographic research: issues of power and representation. Children and Society 18, 165-176.

Christensen, P., James, A., 2000. Research with Children: Perspectives and Practices. Routledge/Falmer, London.

Coyne, I., 1998. Researching children: some methodological and ethical issues. Journal of Clinical Nursing 7, 409-416.

Davis, J., 1998. Understanding the meanings of children: a reflexive process. Children and Society 12, 325-335.

Deatrick, J., Faux, S., 1989. Conducting qualitative studies with children and adolescents. In: Morse, J. (Ed.), Qualitative Nursing Research: A Contemporary Dialogue. Aspen, Rockville, MD.

Department of Health, 2002. Listening, Hearing and Responding: Department of Health Action Plan-Core Principles for the Involvement of Young People. Department of Health, London.

Department of Health and Department for Education and Skills, 2004. The National Service Framework for Children, Young People and Maternity Services (Executive Summary). Department of Health, London.

Dixon-Woods, M., Young, B., Heney, D., 1999. Partnerships with children. British Medical Journal 319, 778-780.

Dixon-Woods, M., Anwar, Z., Young, B., Brooke, A., 2002. Lay evaluation of services for childhood asthma. Health and Social Care in the Community 10, 503-511.

Docherty, S., Sandelowski, M., 1999. Focus on qualitative methods: interviewing children. Research in Nursing and Health 22, 177-185.

Faux, S., Walsh, M., Deatrick, J., 1988. Intensive interviewing with children and adolescents. Western Journal of Nursing Research 10, 180-194.

Freed, L., Ellen, J., Irwin, C., Millstein, G., 1998. Determinants of adolescent's satisfaction with health care providers and intentions to keep follow-up appointments. Journal of Adolescent Health 22, 309-311.

Harden, J., Scott, S., Backett-Milburn, K., Jackson, S., 2000. Can't talk, won't talk: methodological issues in researching children. Sociological Research Online 5, 〈http://www. socresonline.org.uk/5/2/harden.html. $>$

Hill, M., 1997. Participatory research with children. Child and Family Social Work 2, 171-183. 
Horner, S., 2000. Using focus group methods with middle school children. Research in Nursing and Health 23, 510-517.

Hutchby, I., 2005. Children's Talk and Social Competence. Children and Society 19, 66-73.

James, A., 2001. Ethnography in the Study of Children and Childhood. In: Atkinson, P., Coffey, A., Delamont, S., Lofland, J., Lofland, L. (Eds.), Handbook of Ethnography. Sage, London, pp. 246-257.

James, A., Prout, A., 1997. A New Paradigm for the Sociology of Childhood? Provenance, Promise and Problems. In: James, A., Prout, A. (Eds.), Constructing and Reconstructing Childhood, second ed. Routledge/Falmer, London, pp. 7-33.

James, A., Jenks, C., Prout, A., 1998. Theorising Childhood. Polity, London.

Jans, M., 2004. Children as citizens: towards a contemporary notion of child participation. Childhood 11, 27-44.

Kortesluoma., R., Hentinen, M., Nikkonen, M., 2003. Conducting a qualitative child interview: methodological considerations. Journal of Advanced Nursing 42, 434-441.

Kyngas, H., 1998. Adolescent's perceptions of physicians, nurses, parents and friends: help or hindrance in compliance with diabetes self-care. Journal of Advanced Nursing 27, 760-769.

Litt, I., 1998. Satisfaction with health care: the adolescent's perspective. Journal of Adolescent Health 23, 59-60.

Mahon, A., Glendinning, C., Clarke, K., Craig, G., 1996. Researching children: methods and ethics. Children and Society 10, 145-154.

Mauthner, M., 1997. Methodological aspects of collecting data from children: lessons from three research projects. Children and Society 11, 16-28.

Mayall, B., 1994. Negotiating health: children at home and at primary school. Cassell, London.

McCrum, S., Bernal, P., 1994. Interviewing Children: A Training Pack for Journalists. Children's Voices, Buckfastleigh, Devon.

Miller, S., 2000. Researching children: issues arising from a phenomenological study with children who have diabetes mellitus. Journal of Advanced Nursing 31, 1228-1236.

Morrow, V., Richards, M., 1996. The ethics of social research with children: an overview. Children and Society 10, 90-105.
National Children's Bureau, 2003. Guidelines for Research National Children's Bureau, London.

National Institutes of Health, 1997. Policy on the inclusion of children as subjects in clinical research. Office of Extramural Research, National Institutes of Health, Bethesda, MD.

Punch, S., 2002a. Interviewing strategies with young people: the 'secret box', stimulus material and task based activities. Children and Society 16, 45-56.

Punch, S., 2002b. Research with Children-the same or different from research with adults? Childhood 9, 321-341.

Richman, N., 1993. Communicating with Children: Helping Children in Distress. Save the Children Fund, London.

Ronen, G., Rosenbaum, P., Law, M., Streiner, D., 2001. Health related quality of life in childhood disorders: a modified focus group technique to involve children. Quality of Life Research 10, 71-79.

Sloper, P., Lightfoot, J., 2003. Involving disabled and chronically ill children and young people in health service development. Child: Care, Health and Development 29, $15-20$.

Solberg, A., 1996. The challenge in child research: from 'being' to 'doing'. In: Brannen, J., O'Brien, M. (Eds.), Children in Families: Research and Policy. Falmer Press, London.

Thomas, N., O'Kane, C., 1998. The ethics of participatory research with children. Children and Society 12, 336-348.

United Nations, 1989. United Nations Convention on the Rights of the Child. United Nations, Geneva.

Veltman, M., Browne, K., 2002. The assessment of drawings from children who have been maltreated: a systematic review. Child Abuse Review 11, 19-37.

Waksler, F.C., 1991. Beyond Socialisation. In: Waksler, F.C. (Ed.), Studying the Social Worlds of Children: Sociological Readings. Routledge/Falmer, London, pp. 12-22.

Ward, L., 1998. Seen and Heard: Involving Disabled Children and Young People in Research and Development Projects. Joseph Rowntree Foundation, New York.

West, A., 1999. Children's own research: street children and care in Britain and Bangladesh. Childhood 6, 145-155.

Woodgate, R., 2001. Adopting the qualitative paradigm to understand children's perspectives of illness: barrier or facilitator? J Pediatric Nursing 16, 149-161.

Woodgate, R., Kristjanson, L., 1996. My hurts: hospitalised young children's perceptions of acute pain. Qualitative Health Research 6, 184-201. 